Journal of Advanced College of Engineering and Management, Vol. 5, 2019

\title{
DETERMINING THE HOSTING CAPACITY OF SOLAR PHOTOVOLTAIC IN A RADIAL DISTRIBUTION NETWORK USING AN ANALYTICAL APPROACH
}

\author{
Suraj Dahal ${ }^{1}$, Ajay Kumar Jha ${ }^{2}$, Nawraj Bhattarai ${ }^{3}$, Anil Kumar Panjiyar ${ }^{4}$ \\ ${ }^{1}$ Electrical Engineer, Department of Electrical Engineering, IOE, TU \\ ${ }^{2,3}$ Asst. Professor, Department of Mechanical Engineering, IOE, TU \\ ${ }^{4}$ Lecturer,Department of Electrical Engineering, IOE,TU

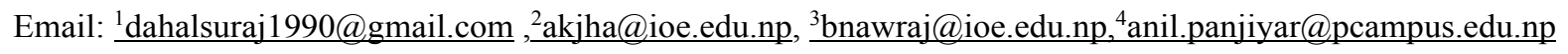

\begin{abstract}
Integrating high photovoltaic (PV) on distribution grid system has a positive impact by significantly reducing the losses and improving the voltage profile at the same time reducing the pollution of the environment However, integrating high proportions of PV in the distribution grid can bring the grid to its operational limits and result in power quality issues. The maximum PV capacity that can be integrated without incurring any grid impacts is referred to as the PV hosting capacity of the grid. This paper intends to evaluate the hosting capacity of solar PV in Dodhara-Chandani (DoC) distribution feeder as one of the feeder of Integrated Nepal Power System (INPS), considering grid parameters and operating condition in Nepal. Three main criteria were investigated for determining the hosting capacity of PV; reverse power flow, maximum voltage deviation of feeder and current carrying limit of conductor. The analysis has been performed by means of static load-flow simulation in Electrical Transient \& Analysis Program (ETAP) and coding in MATLAB R2017a. The study shows that PV of rated capacity $687 \mathrm{kWp}$ can be installed at a point of interconnection (POI) whereas an optimal placement of solar PV is found to be at 18 th node (in between starting and end of the feeder) considering minimum system losses. The minimum voltage profile at end of the feeder has improved by $8 \%$ while the active power loss reduction of network has reduced by $83.6 \%$ after the integration of solar PV. The results indicate voltage at different buses and the ampacity of most of the conductors have been improved after the integration of PV system into DoC feeder.
\end{abstract}

Key words:Penetration level, photovoltaics (PV), point of interconnection (POI), and hosting capacity.

\section{Introduction}

One of the technology use to generate electricity in a renewable way is to use solar cells to convert the energy delivered by the solar irradiance into electricity. The progress in new technologies in the last few years has led to a significant decrease in the price of PV panels. Due to this the large scale of solar PV is of rising interest both in the national and global context. In 2005, the global installed capacity of solar PV was 5.1GW, which had increased about 60 times by the year 2016 approximating the total global capacity to $303 \mathrm{GW}$ of which $75 \mathrm{GW}$ (up $48 \%$ over 2015 ) has been added last year only[11]. This accelerated growth of grid connected solar PV signifies the importance of grid connected solar PV system throughout the world. Moreover, the technical benefits include improvement of voltage, loss reduction, relieved transmission and distribution congestion, improved utility system reliability and power quality, increasing the durability of equipment, improving power quality[2].However, solar PV systems integration in the distribution networks has led to some technical challenges such as reverse power flow and overvoltage as the power flows through the less resistible path. Moreover, the violation of the voltage profile may lead to the instability of the electric system [10], [15], all the distribution grid can host certain amount of solar PV without incurring any grid called it as hosting capacity of that grid. The hosting capacity of each network differ from one another and depends on various parameters of the feeder. The grid upgradation in terms of line, line regulator needs to be done if the integration of solar PV beyond the hosting capacity is needed[14].The intense of this research is to find the hosting capacity of a radial distribution network $(\mathrm{RDN})$. 


\section{Literature Review}

Hosting capacity is correlated to optimal placement and sizing of solar PV while integrating into the grid and various methods have been proposed for it. The optimization technique in heuristic methods are the Genetic Algorithm which uses the strings instead of manipulating the objects themselves to get the results, but the principal challenge is coding of these objects into strings which may take a long time[7]. In [14]have suggested the smart method comprising of Binary Genetic Algorithm (BGA) and Bacteria Foraging Algorithm (BFA) for DG placement in the distribution network, their approach was the bridge by combining two different algorithms. In, [4], the authors used the metaheuristic method $\mathrm{ABC}$ for the optimal placement and sizing of DG for power loss reduction and improved voltage profile. The authors in[1] proposed a simple analytical method based on iterative search technique and Newton-Raphson method for the optimal sizing and allocation of DG in a network to lower the cost and loss effectively. The metaheuristic population-based algorithms are to be fast and required less storage, but they are probability based so their results cannot be guaranteed due to so many manipulations of parameters and they depend on the analytical equations. They used the analytical methods as benchmark methods.

Load flow analysis is a necessary basic tool for any electrical power system under steady state condition for determining the exact electrical performance. It helps to determine the real and reactive power losses, the amount of current flowing through the lines, and the voltage magnitude and phase angle at different nodes. It is important in the planning of the new power installation and upgrading or extension of the existing power system, thus the results of the load flow is the starting point for other analyses of the electric power system[16]. Distribution system with large number of buses have high $\mathrm{R} / \mathrm{X}$ ration, thus decupling assumptions are not valid. So, the conventional Newton Raphson and Fast Decouple methods fail to effectively evaluate the load flow analysis, thus the load flow analysis in the radial network can be done by using the BFPM which has proved to be very effective. Starts with some assumed voltages at each bus, except the source node. In the backward propagation, adds all the load currents and downstream branch currents (computed at the assumed voltages) to compute current in the upstream branch. Starting from the source node, in the forward propagation, updates the bus voltages utilizing the branch currents computed in the backward propagation. Backward-forward propagation continues till voltages at all the buses converge within pre-specified tolerance. The method is based on computation of Bus-Injection to Branch-Current (BIBC) Matrix and BranchCurrent to Bus-Voltage (BCBV) Matrix. The BIBC matrix is responsible for the variation between the bus current injection and branch current, and the $\mathrm{BCBV}$ matrix is responsible for the variation between the branch current and bus voltage [8].

\section{Methodology Approach}

\section{Formulation of the objective function}

The objective function of this study is to minimize the total branch loss as follows [12]:

Minimize, $P_{T L}=\sum_{y=1}^{N} I_{y}{ }^{2} \times R_{y}$

Equation (1)

Where, $P_{T L}$ is total active power losses in the system, $I_{y}$ is the current magnitude flowing from node $y$ to node $y+1, R_{y}$ is the resistance of branch y and $N$ is the total number of branches.

The main objective function is subjected to inequality constraints which are tabulated below: 
Table 1: Impact constraints and thresholds

\begin{tabular}{|l|l|}
\hline Impact constraints & Defined thresholds \\
\hline Bus voltage & 0.95 p.u. $\leq|\mathrm{V}| \leq \mid 1.05$ p.u. \\
\hline Feeder capacity limit & $\left|\mathrm{I}_{\mathrm{y}}\right| \leq\left|\mathrm{I}_{\mathrm{ymax},}\right|$ \\
\hline Reverse power flow & Power reversal at the substation transformer \\
\hline
\end{tabular}

\section{Optimization Technique For The Integration of Solar PV Into The Grid}

An analytical optimization technique called maximum active power loss saving of lines is used to find an optimal placement and sizing of solar PV into the grid, where it evaluates the current injected at each node and calculates the power losses saving when this current is injected at that node.

Consider a network of $\mathrm{N}$ branches, if solar PV is placed at node ' $\mathrm{m}$ ' from the substation and $\beta$ set branches are branches located between the source node and the node at which solar PV of injection current 'Is' is placed. The current flow in $\beta$ branch set will be changed by the solar PV current injected while the current flowing in the rest of the network remains unaffected. The total active power loss in the system before solar PV integration in the network can be calculated using equation 1.Furthermore, the total active power loss in the system with an integration of the solar PV at node ' $m$ ' in the radial distribution network is computed as follow:

$$
\left(\mathrm{P}_{\mathrm{TLPV}}\right)_{\mathrm{m}}=\sum_{\mathrm{y}=1}^{m}\left(\mathrm{I}_{\mathrm{y}}-\mathrm{I}_{\mathrm{S}}\right)^{\wedge} 2 * \mathrm{Ry}+\sum_{\mathrm{y}=\mathrm{m}+1}^{\mathrm{N}} \mathrm{I}_{\mathrm{y}}^{2} * \mathrm{R}_{\mathrm{y}}
$$

Now the active power saving at each node is calculated by subtracting the total power loss with solar PV from the total based loss without solar PV as shown below:

Saving $(\mathrm{Ps})=\mathrm{P}_{\mathrm{TL}}-\left(\mathrm{P}_{\mathrm{TLPV}}\right)_{\mathrm{m}}$

$$
\text { Ps }=-2 \text { Is } \sum_{\mathrm{y}=1}^{m} \mathrm{Iy} * \mathrm{R}_{\mathrm{y}} \quad-I s^{2} * \sum_{\mathrm{y}=1}^{\mathrm{m}} \mathrm{R}_{\mathrm{y}}
$$

The maximum value of power saving is found by equating to zero the derivative of the power saving with respect to its equivalent solar PV current injected at node $\mathrm{m}$.

$\frac{\partial \mathrm{Ps}}{\partial \mathrm{Is}}=-2 \sum_{\mathrm{y}=1}^{m} \mathrm{Iy} * \mathrm{R}_{\mathrm{y}} \quad-2 I s * \sum_{\mathrm{y}=1}^{\mathrm{m}} \mathrm{R}_{\mathrm{y}}=0$

Equation (4)

$\mathrm{Is}=\frac{-\sum_{\mathrm{y}=1}^{m} I \mathrm{y} * \mathrm{R}_{\mathrm{y}}}{\sum_{\mathrm{y}=1}^{\mathrm{m}} \mathrm{R}_{\mathrm{y}}}$

Equation (5)

From equation 5, the value of the current injected at each node can be evaluated respectively and these computed current values are replaced in equation 3 for all the nodes, then the node with higher power saving is identified and selected as candidate for Solar PV placement. The optimal solar PV size at selected node $\mathrm{m}$ is calculated using the current injected at optimal branchand its corresponding voltage magnitude as: 
$(\mathrm{Pspv})_{\mathrm{m}}=\frac{-|\mathrm{V}| \sum_{\mathrm{y}=1}^{\mathrm{m}} \mathrm{Iy} * \mathrm{R}_{\mathrm{y}}}{\sum_{\mathrm{y}=1}^{\mathrm{m}} \mathrm{R}_{\mathrm{y}}}$

Equation (6)

The flowchart of maximum power loss saving technique is shown in Fig 1

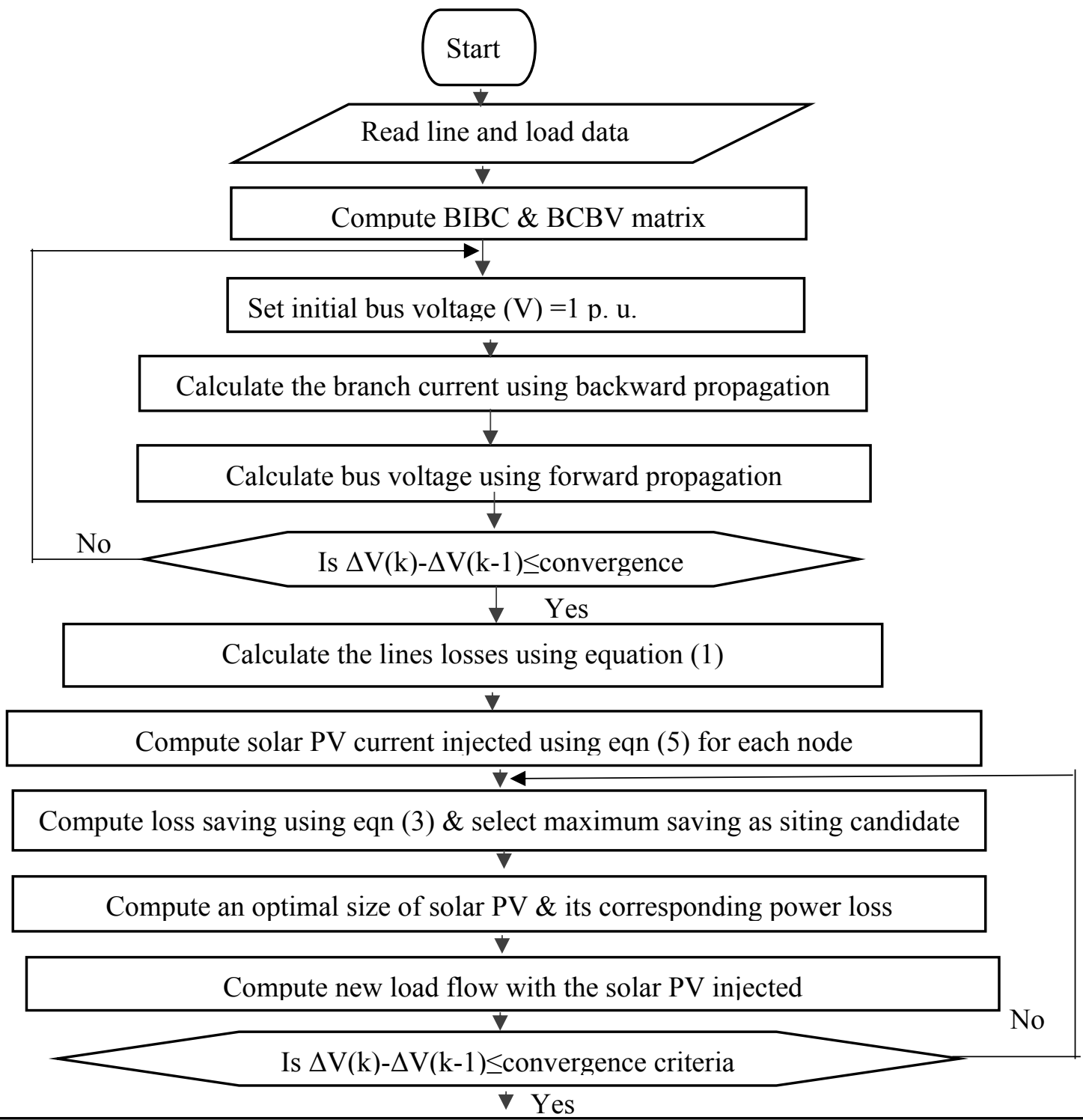

Print minimum loss and bus no.at which minimum loss occurs and solar PV hosting capacity

End

Fig 1: Flow chart for optimal sizing and placement of solar PV in RDN

4.

\section{Grid Configuration}

The selected real network 'Dodhara-Chandani Feeder' and analyzed in this paper is one of the feeder of Mahendranagar Distribution and Consumer Service(DCS) of Nepal where the end-user to this part 
of the grid are mainly commercial and domestic ones.This is an $11 \mathrm{kV}$ distribution feeder with 44 number of buses,which receives power from 5MVA, 33/11 kV power transformer situated at Dodhara-Chandani distribution substation. The line conductor used in proposed network is weasel ACSR (129 A,30 mm²). Load and line data of DoC feeder has been attached as Appendix-A.

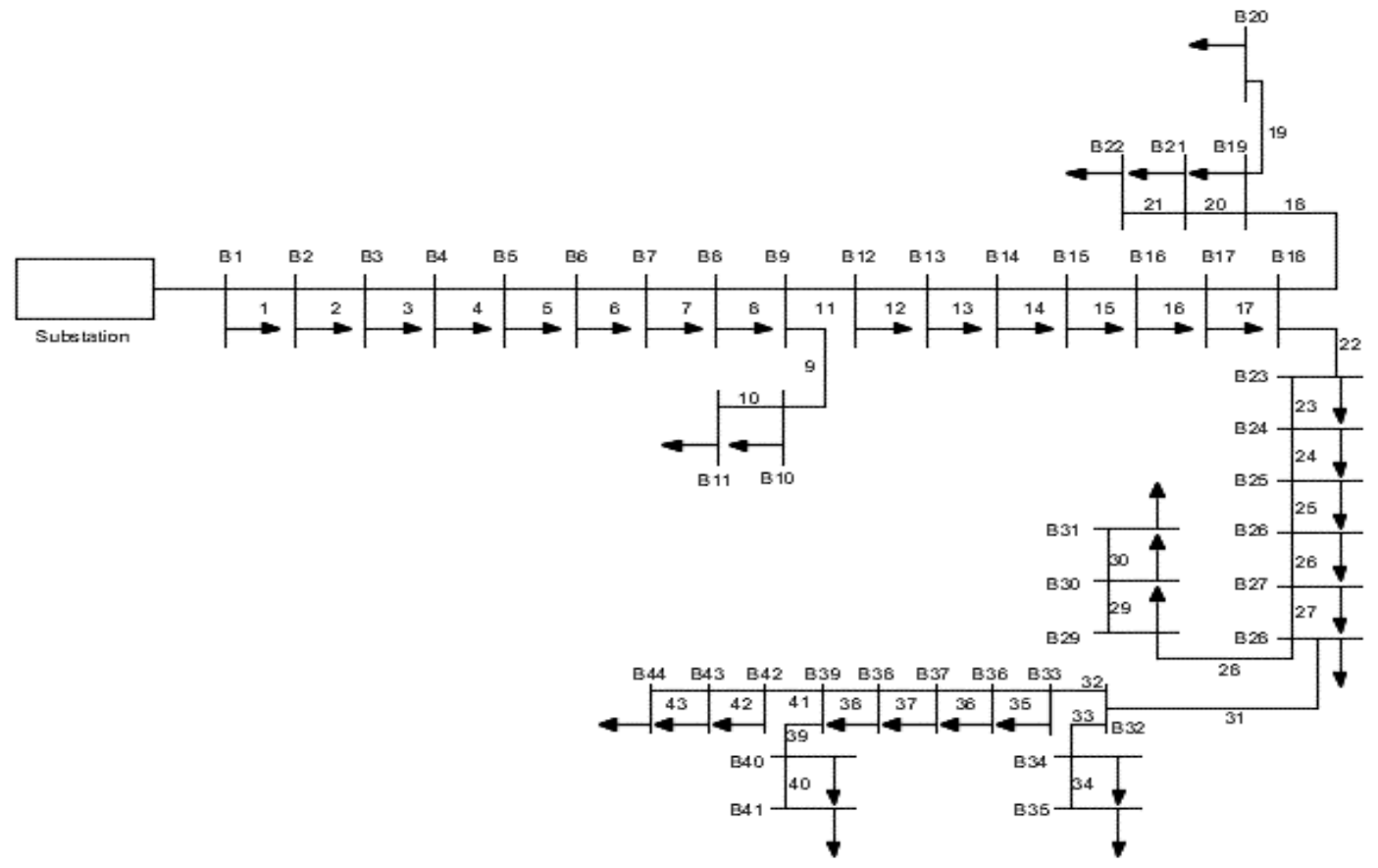

Fig 2: Single line diagram of DoC feeder

\section{Load Profile}

Among the four seasons, summer season has been used for this analysis because it has the highest load as shown in Fig 3. A minimum representative loading $(899 \mathrm{~kW})$ at $1 \mathrm{pm}$ which is $65 \%$ loading to that of absolute load $(1374 \mathrm{~kW})$ at $8 \mathrm{pm}$ is chosen as the PV integration time to the grid because during this time voltage of the grid is already high so that the grid operation limit would not be incurred.

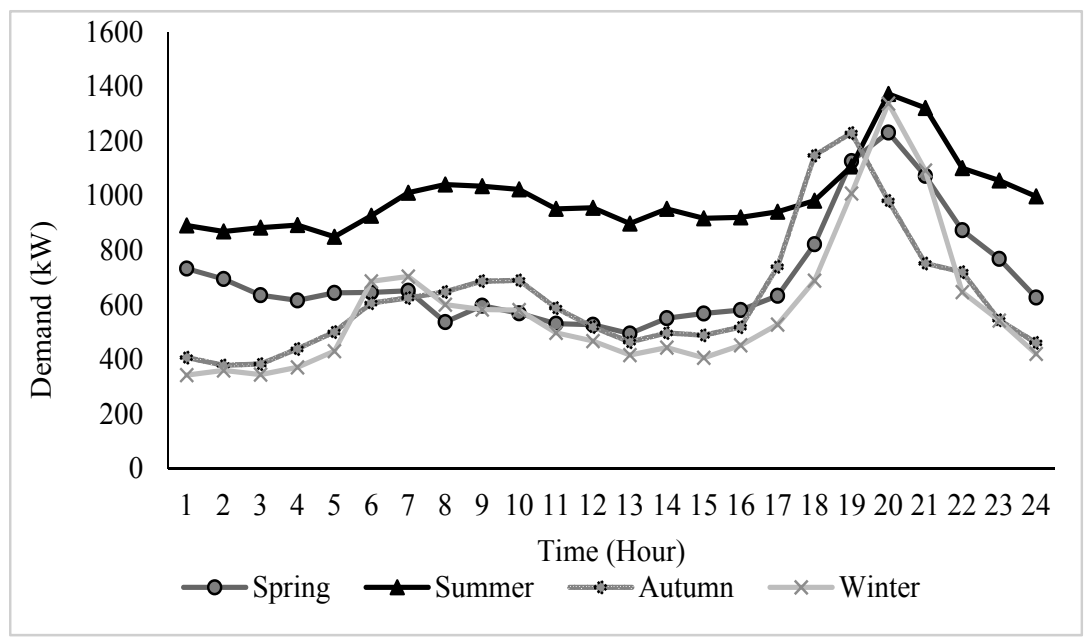

Fig 3 : Average daily demand of 2017/18 for various seasons of DoC feeder. (Source: Mahendranagar DCS, 2017/18)

\section{Results and Discussion}

Modelling of the existing proposed feederin ETAP is done using grid parameters. The static load flow analysis of proposed feeder for summer season was performed considering both the cases, with and 
without PV. This analysis tests whether the steady state operating constraints are violated along with the penetration of solar PV at various interconnection during different study cases. The results analysis of single solar PV optimal placement and sizing were carried out with the help of MATLAB R2017a coding, and the comparisons were made with the existing methods. Based on these analysis, the hosting capacity of the Dodhara-Chandani RDN was determined.The initial load flow simulation without integration of solar photovoltaic was carried out under ETAP and the summary of the result is presented in Table 2.

Table 2: Base load flow result of Dodhara-Chandani feeder and tested system

\begin{tabular}{|l|l|}
\hline Total load (kVA) & $897+\mathrm{j} 395$ \\
\hline Total active loss of line (kW) & 73.28 \\
\hline Minimum voltage (p.u.) & 0.9046 p.u. \\
\hline Minimum voltage occurred at bus no. & 44 \\
\hline
\end{tabular}

\section{Optimal Placement and Sizing of a Solar PV}

With an implication of maximum power saving analytical optimization approach an optimal placement and sizing of a solar PV into the grid is evaluated using MATLAB R2017a and is summarized inTable 3 .

Table 3: Summary of optimal placement and sizing of SPV injected into the grid

\begin{tabular}{|l|l|}
\hline Optimal siting (node no.) & 18 \\
\hline Optimal size (kW) & 687 \\
\hline Total active power loss of line (kW) & 12.02 \\
\hline Minimum voltage occurred node number & 43 \\
\hline Minimum voltage (p.u.) & 0.977 \\
\hline
\end{tabular}

An optimal size of solar PV thus obtained from MATLAB is simulated into ETAP again and results are obtained.

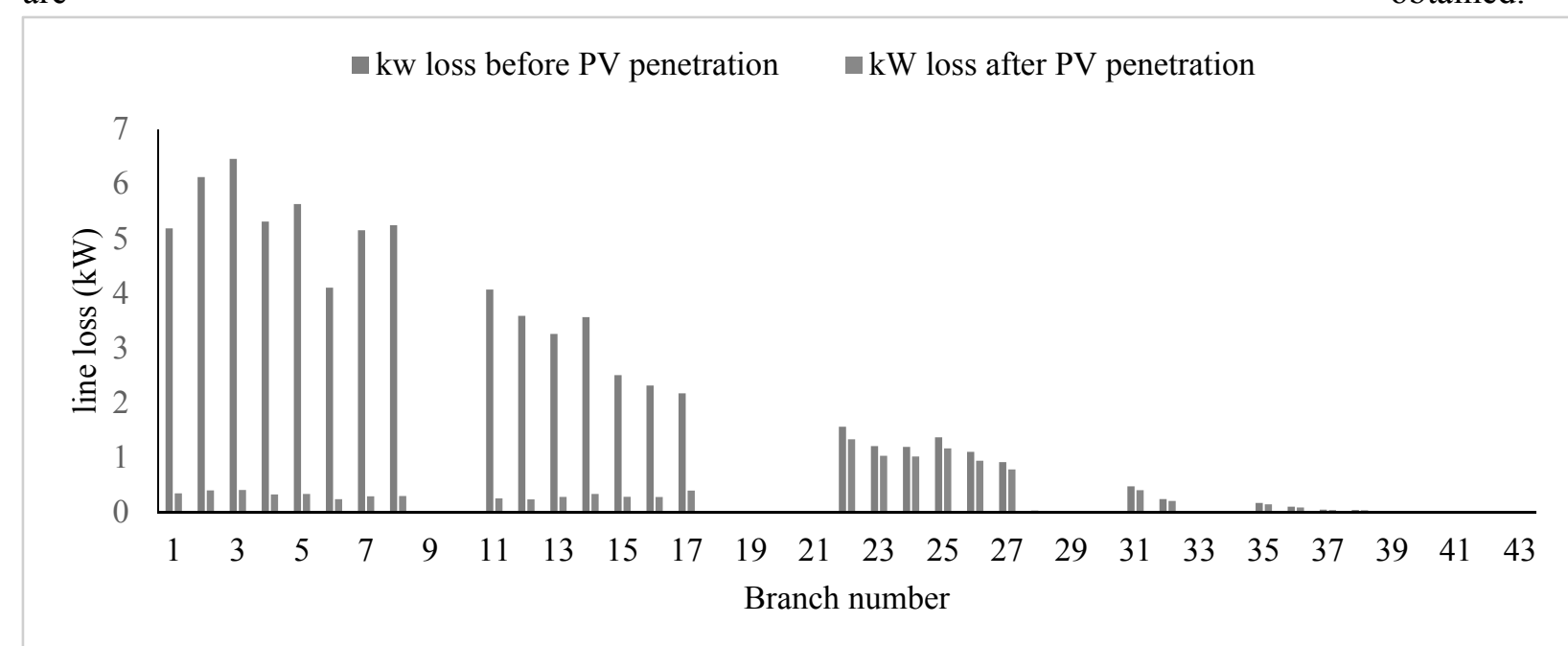


Fig 4: kW losses of lines comparison after penetration of SPV into DoC feeder

The active power losses in the branches located between the source and the nodeat where the solar PV was placed have drastically reduced due to the injection of active power by PV. It is about six times lesser than the initial losses. However, beyond the optimal node, there was only a slight power loss reduction.

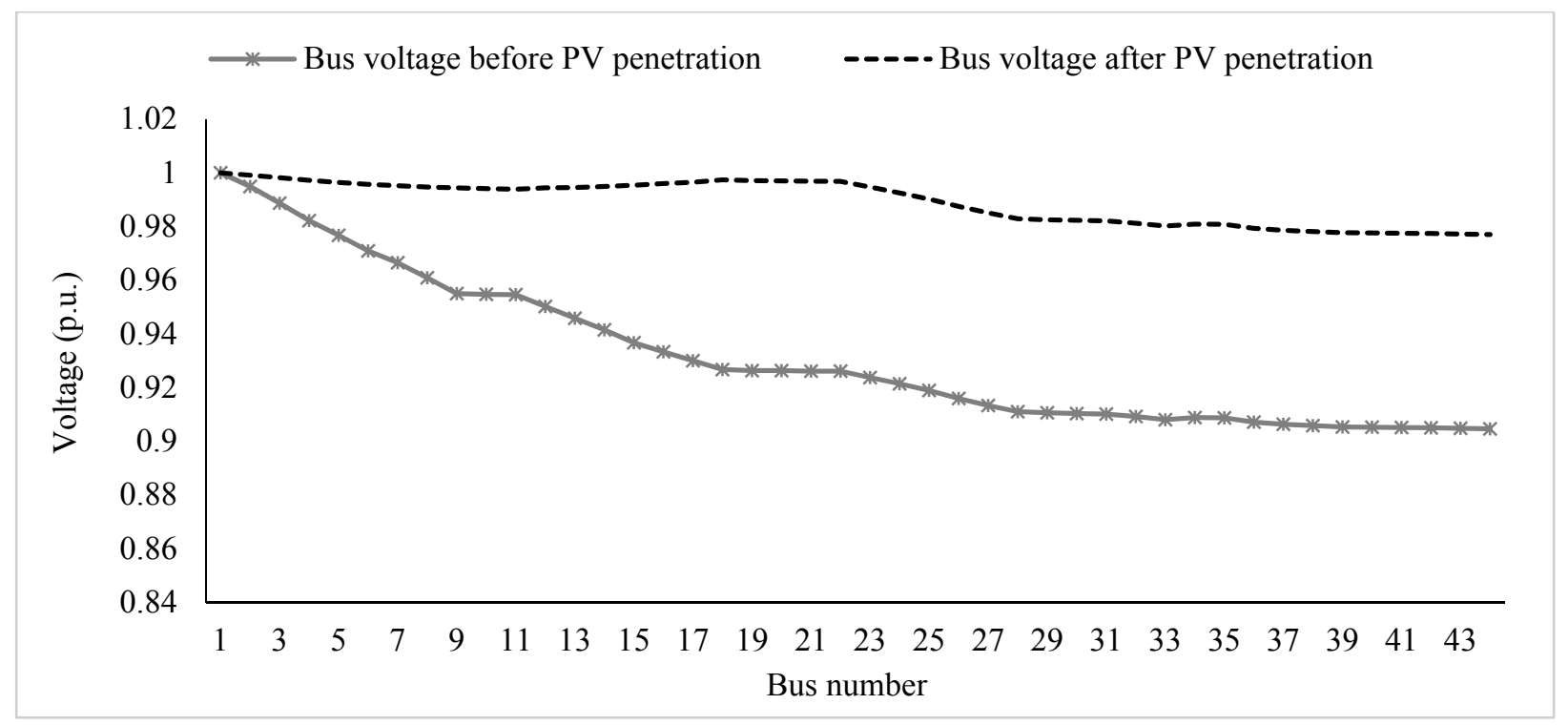

Fig 5: Comparison of bus voltage when PV penetrated into DoC feeder

An integration of solar PV has improved the whole network voltage profile and has reduced the overall current magnitude flowing in the network, thus the voltage drop across the distribution lines has been decreased. The minimum voltage profile at 43 node of DoC feeder, has improved by $8 \%$, after an integration of solar PV into the grid. 


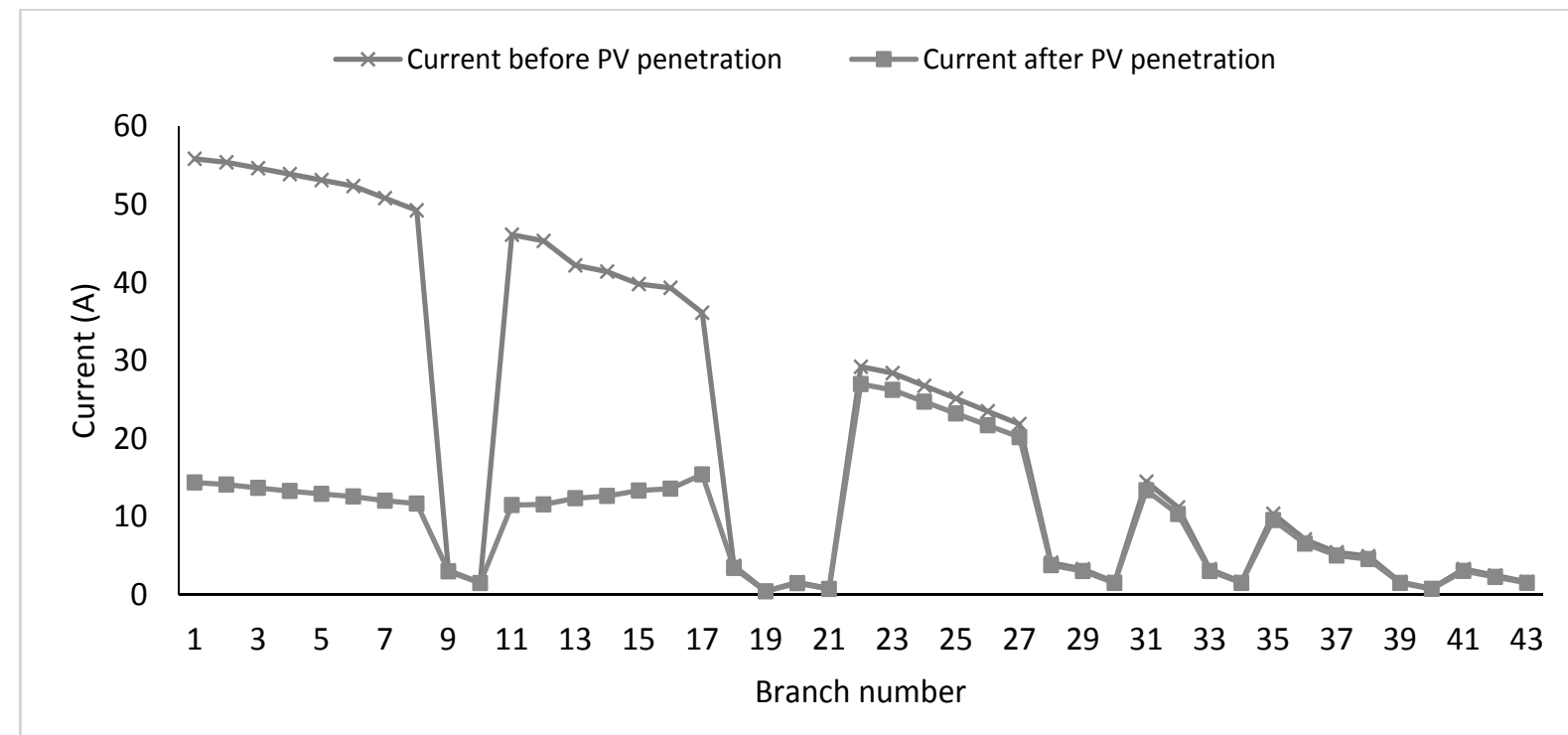

Fig 6: Comparison of bus line current when PV penetrated into DoC feeder

The solar PV integrated has supplied the total or part of that particular zone load demand, hence reducing the current flow from the source to a load of a given location. Graph above showed that the ampacity of the line conductors (lines between substation and POI) increased when solar PV is integrated into the grid.

\section{Conclusion}

Location and capacity of solar PV are the two important parameters for the computation of hosting capacity of solar PV in any system. An analytical optimization method based on the maximum power saving method was used for the single solar PV system placement and sizing. The analysis of the results showed that the solar PV must be placed in particular location in order to get minimum losses. So, hosting capacity of solar PV into the Dodhara-Chandani feeder with minimum loss is found to be $687 \mathrm{kWp}$ at node 18 . The integration of the solar PV in the system has reduced the active power loss by $83.6 \%$ for DoC feeder. The voltage profile of weak bus has increased by $0.0724 \mathrm{p}$.u. The proposed method for determining the hosting capacity of Solar PV into the grid is tested into IEEE33-bus standard system[9] and is compared with existing methods where the proposed method is found satisfactory to others.

Table 4: Comparison of different methods for optimal placement and sizing of Solar PV into IEEE33bus-tested system

\begin{tabular}{|l|l|l|l|l|}
\hline Method used & ABC [3] & Firefly [5] & IA [9] & Proposed method \\
\hline Optimal bus no. & 6 & 30 & 6 & 6 \\
\hline Optimal size (kWp) & 2400 & 1190.4 & 2601 & 2474 \\
\hline Loss reduction (\%) & 48.20 & 48.74 & 47.39 & 47.8 \\
\hline Voltage profile at 18 node (p.u.) & 0.964 & 0.9398 & 0.9425 & 0.9484 \\
\hline
\end{tabular}


Hence, the integration of solar system in the distribution system reduces the losses and improving the voltage profile at the same time the line loading capacity of the network increases.

\section{Recommendations}

This study considers the active power flow into the system, however areas like frequency control and reactive power control also needs to be considered in further studies.

$\square \quad$ Transient analysis is not included therefore, while doing further study in future one can do the transient analysis considering the role of protective devices with proper ratings.

$\square$ Computation of energy loss technique would be the better option to power loss technique while determining an optimal placement of solar PV.

\section{References}

[1]. A. Alhamali, D. M. E. Farrag and D. Bevan, "'Determination of Optimal Site and Capacity of DG Systems in Distribution Network based on Genetic Algorithm"," Heraklion, Greece, 2017.

[2]. A. Samadi, "'Large Scale Solar Power Integration",Doctoral Thesis," Stockholm, 2014.

[3]. A.-M. F. S. and M. E. E. Hawary, "'Modified Artificial Bee Colony Algorithm for Optimal Distributed Generation Sizing and Allocation in Distribution Systems"," in IEEE Electrical Power \& Energy Conference (EPEC), Canda, 2010.

[4]. B. Nagaraju, K. S. Padmini and D. V. Rao, "'Optimal Placement of SPV based DG for Loss Reduction in Radial Distribution System Using Direct Search Algorithm"," International Journal of Conceptions on Electrical and Electronics Engineering, vol. III, no. 1, pp. 23459603, 2012.

[5]. D. Q. Hung and N. Mithulananthan,, "'Multiple Distributed Generator Placement in Primary Distribution Networks for Loss Reduction"," IEEE Transactions on Industrial Electronics, vol. 60, no. 4, pp. 1700-1708, 2011.

[6]. D. Q. Hung, "'Smart Integration of Distributed Renewable"," Australia, 2014.

[7]. D. Q. Hung, "Smart Integration of Distributed Renewable Generation and Battery Energy Storage", Queensland: The University of Queensland, Australia, 2014.

[8]. J. M. Rupa and GaneshS., "'Power Flow Analysis for Radial Distribution Networks Using Backward/Forward Sweep Method"," International Journal of Electrical, Computer, Energetic, Electronic and Communication Engineering, vol. 8, no. 10, pp. 1621-1625, 2014.

[9]. K. Nadhir, D. Chabane and B. Tarek, "'Firefly algorithm based energy loss minimization approach for optimal sizing \& placement of distributed generation"," Canada, 2013.

[10]. R. A. Shalwala and J. M. Bleijs, "Impact of Grid-Connected PV Sytems in Residential Areas in Saudi Arabin", Leiccester: IEEE, 2010.

[11]. REN212017, "'Renewables 2017 Global Status Report"," REN21 Secretariat, Paris, 2017. 
[12]. S. Ghosh, P. Sakti and G. Sardined, "'Optimal sizing and placement of distributed generation in a network system."," International Journal of Electrical Power \& Energy Systems, vol. 32, no. 8, pp. 849-856, 2010.

[13]. S. H. Zadeh, O. Z. Nejad and S. Hasam, "'Optimal DG Placement for Power Loss Reduction and Improvement Voltage Profile Using Smart Methods"," International Journal of Smart Engineering", vol. 01, no. 3, pp. 2251-9246, 2012.

[14]. S. Jothibasu, S. Santoso and A. Dubey, "'Determining PV Hosting Capacity without Incurring Grid Integration Cost"," Canada, 2016.

[15]. T. Alquthami, H. Ravindra, M. Faraque and M. Steurer, "'Study of Photovoltaic Integration Impact on System Stability Using Custom Model of PV Arrays Integrated with PSS/E"," North American Power Symposium (NAPS), 2010.

[16]. W. D. Stevenson and J. J. Grainger, "Power System Analysis", 2nd ed., New York: Mc Graw Hill Education, 2003.

Appendix-A : Line and load data of DoC feeder

\begin{tabular}{|c|c|c|c|c|c|c|c|}
\hline \multirow{2}{*}{ Br.no } & \multirow{2}{*}{$\begin{array}{c}\text { Sen.node } \\
\text { (s.n.) }\end{array}$} & \multirow{2}{*}{$\begin{array}{c}\text { Rec.node } \\
\text { (r.n.) }\end{array}$} & \multicolumn{2}{|c|}{ Load at $100 \%$ loading } & \multirow{2}{*}{$\begin{array}{c}\text { Tr.kVA } \\
\text { (r.n.) }\end{array}$} & \multirow{2}{*}{$\mathbf{R}(\mathbf{o h m})$} & \multirow{2}{*}{ X (ohm) } \\
\hline & & & PL kW (r.n.) & QL kVAr (r.n.) & & & \\
\hline 1 & 1 & 2 & 12 & 5 & 15 & 0.4539 & 0.1449 \\
\hline 2 & 2 & 3 & 20 & 8 & 25 & 0.5446 & 0.1739 \\
\hline 3 & 3 & 4 & 20 & 8 & 25 & 0.5900 & 0.1884 \\
\hline 4 & 4 & 5 & 20 & 8 & 25 & 0.4992 & 0.1594 \\
\hline 5 & 5 & 6 & 20 & 8 & 25 & 0.5446 & 0.1739 \\
\hline 6 & 6 & 7 & 40 & 16 & 50 & 0.4085 & 0.1304 \\
\hline 7 & 7 & 8 & 40 & 16 & 50 & 0.5446 & 0.1739 \\
\hline 8 & 8 & 9 & - & - & - & 0.5900 & 0.1884 \\
\hline 9 & 9 & 10 & 40 & 16 & 50 & 0.4765 & 0.1521 \\
\hline 10 & 10 & 11 & 40 & 16 & 50 & 0.4992 & 0.1594 \\
\hline 11 & 9 & 12 & 20 & 8 & 25 & 0.5219 & 0.1666 \\
\hline 12 & 12 & 13 & 79 & 32 & 100 & 0.4765 & 0.1521 \\
\hline 13 & 13 & 14 & 20 & 8 & 25 & 0.4992 & 0.1594 \\
\hline 14 & 14 & 15 & 40 & 16 & 50 & 0.5673 & 0.1811 \\
\hline 15 & 15 & 16 & 12 & 5 & 15 & 0.4312 & 0.1377 \\
\hline 16 & 16 & 17 & 79 & 32 & 100 & 0.4085 & 0.1304 \\
\hline 17 & 17 & 18 & 79 & 32 & 100 & 0.4539 & 0.1449 \\
\hline 18 & 18 & 19 & 40 & 16 & 50 & 0.4765 & 0.1521 \\
\hline 19 & 19 & 20 & 12 & 5 & 15 & 0.5446 & 0.1739 \\
\hline 20 & 19 & 21 & 20 & 8 & 25 & 0.5219 & 0.1666 \\
\hline
\end{tabular}




\begin{tabular}{|c|c|c|c|c|c|c|c|}
\hline 21 & 21 & 22 & 20 & 8 & 25 & 0.5446 & 0.1739 \\
\hline 22 & 18 & 23 & 20 & 8 & 25 & 0.4992 & 0.1594 \\
\hline 23 & 23 & 24 & 40 & 16 & 50 & 0.4085 & 0.1304 \\
\hline 24 & 24 & 25 & 40 & 16 & 50 & 0.4539 & 0.1449 \\
\hline 25 & 25 & 26 & 40 & 16 & 50 & 0.5900 & 0.1884 \\
\hline 26 & 26 & 27 & 40 & 16 & 50 & 0.5446 & 0.1739 \\
\hline 27 & 27 & 28 & 79 & 32 & 100 & 0.5219 & 0.1666 \\
\hline 28 & 28 & 29 & 20 & 8 & 25 & 0.4765 & 0.1521 \\
\hline 29 & 29 & 30 & 40 & 16 & 50 & 0.4312 & 0.1377 \\
\hline 30 & 30 & 31 & 40 & 16 & 50 & 0.5446 & 0.1739 \\
\hline 31 & 28 & 32 & - & - & - & 0.6127 & 0.1956 \\
\hline 32 & 32 & 33 & 20 & 8 & 25 & 0.5219 & 0.1666 \\
\hline 33 & 33 & 34 & 40 & 16 & 50 & 0.4992 & 0.1594 \\
\hline 34 & 34 & 35 & 40 & 16 & 50 & 0.5446 & 0.1739 \\
\hline 35 & 33 & 36 & 79 & 32 & 100 & 0.4312 & 0.1377 \\
\hline 36 & 36 & 37 & 40 & 16 & 50 & 0.5446 & 0.1739 \\
\hline 37 & 37 & 38 & 12 & 5 & 15 & 0.4312 & 0.1377 \\
\hline 38 & 38 & 39 & - & - & - & 0.4629 & 0.1478 \\
\hline 39 & 39 & 40 & 20 & 8 & 25 & 0.4765 & 0.1521 \\
\hline 40 & 40 & 41 & 20 & 8 & 25 & 0.5219 & 0.1666 \\
\hline 41 & 39 & 42 & 20 & 8 & 25 & 0.4992 & 0.1594 \\
\hline 42 & 42 & 43 & 20 & 8 & 25 & 0.4765 & 0.1521 \\
\hline 43 & 43 & 44 & 40 & 16 & 50 & 0.5446 & 0.1739 \\
\hline
\end{tabular}

